\title{
Geographic Variations in the Prevalence Rates of Parkinson's Disease in Alberta
}

\author{
Lawrence W. Svenson, G. Howard Platt and Sheena E. Woodhead
}

\begin{abstract}
Parkinson's disease prevalence rates were examined for the Province of Alberta by age, sex and census division. Using the claims administrative data from the Alberta Health Care Insurance Plan, a cohort of all registered individuals (2.4 million) was extracted and followed for the five year period, April 1, 1984 to March 31, 1989. No new members were added to the cohort and an attrition rate averaging $6 \%$ per year was observed. The overall crude prevalence rates of 248.9 and 239.8 per 100,000 population were noted for males and females respectively. Both sexes were found to have a statistically significant variation across Alberta's 19 census divisions. For males, examination of standardized morbidity ratios found a low risk of Parkinson's disease associated with five census divisions, of which two contained Alberta's two largest cities. An excess risk was associated with four primarily rural census divisions. Females, on the other hand, had a low risk associated with one rural census division and excess risk in four census divisions. The uneven distribution within Alberta offers support for an environmental theory of etiology which may be associated with rural living.
\end{abstract}

RÉSUMÉ: Variations géographiques dans les taux de prévalence de la maladie de Parkinson en Alberta. Nous avons examiné les taux de prévalence de la maladie de Parkinson (MP) selon l'âge, le genre et la division de recensement dans la province d'Alberta. A partir des données administratives de réclamations du plan d'assurance maladie de l'Alberta, une cohorte comprenant tous les individus enregistrés ( 2.4 millions) a été constituée et suivie sur une période de 5 ans, du $1^{\mathrm{cr}}$ avril 1984 au 31 mars 1989. Nous n'avons pas ajouté de nouveaux sujets à la cohorte et un taux d'attrition annuel moyen de $6 \%$ a été observé. Des taux bruts de prévalence totale de 248.9 et 239.8 par 100,000 de population ont été observés pour les hommes et pour les femmes respectivement. Une variation statistiquement significative des taux a été observée pour les deux genres à travers les 19 divisions de recensement de l'Alberta. Pour les hommes, un examen des taux standardisés de morbidité a montré un risque faible de MP dans 5 divisions de recensement, dont deux contiennent les deux plus grandes villes de l'Alberta. Un excès de risque était associé à 4 divisions de recensement principalement rurales. Pour les femmes, un risque faible était associé à une division de recensement rurale et un excès de risque dans 4 divisions de recensement. Une distribution inégale à travers l'Alberta supporte la théorie d'une étiologie environnementale qui pourrait être associée à la vie en milieu rural.

Can. J. Neurol. Sci. 1993: 20: 307-311

Parkinson's disease (PD) is a chronic neurological disorder characterized by a resting tremor, rigidity and bradykinesia. ${ }^{1.2}$ Consistently ranked among the ten most commonly diagnosed neurological disorders, PD accounts for approximately $2.6 \%$ of all neurological diagnoses. ${ }^{3}$ The mean annual incidence and prevalence rates have been estimated at 20 and 300 per 100,000 population respectively ${ }^{4}$ with a mean age of onset, in Canada, estimated at 52 years. Although some studies have found no sex difference, 5,6 males are generally found to have both higher prevalence and mortality. 4.7-16

Hospitalizations for PD can be frequent and the length of each stay long. For example, between 1979 and 1985, the average length of hospitalization in Canada was 104 days (87 days for males; 122 days for females). ${ }^{15}$ Also, $81 \%$ of hospitalizations for PD were among patients aged 65 years or older with an average hospital stay of 111 days ( 92 days for males; 130 days for females). ${ }^{15}$

Since its description in 1817 by James Parkinson, the etiology of PD has been elusive. Three general theories have been proposed to account for etiology: genetic factors, infective and immunological factors, and environmental factors. ${ }^{17.18}$ Researchers have actively searched for a genetic component in the etiology of PD since the early twentieth century. ${ }^{19}$ While Golbe et al. ${ }^{20}$ have reported what may be an autosomal dominant sub-type of PD, genetic investigations examining concordance and incidence rates in twin and familial studies failed to support a genetic

From the Provincial Medical Consultant's Office, Alberta Health, Edmonton

Received April 6, 1993. Accepted in final form July 9, 1993

The views and opinions expressed in this paper are those of the authors and do not necessarily reflect the views or policies of Alberta Health or of the Government of Alberta

Reprint requests to: Larry Svenson, Provincial Medical Consultant's Office, Alberta Health, Box 2222, 18th Floor, 10025 Jasper Avenue, Edmonton, Alberta, Canada T5J 2P4 
model. ${ }^{21-25}$ However, this does not rule out the possibility of a genetic component in a multifactorial etiology. It does imply that if genetics are involved, it is likely in terms of susceptibility and not in the form of a gene specific for PD.

Infective factor models have received support from studies examining the prevalence of PD among individuals who survived the influenza epidemics during 1918-1926. ${ }^{26.27}$ Although some support exists for an infective factor model, rates found in studies of this model fail to account for a significant proportion of current PD cases. ${ }^{26.27}$

As a result of the lack of evidence implicating either genetic or infective models, researchers have recently focused on an environmental factor (toxin) theory of etiology. The environmental theory of etiology received support with the discovery that 1-methyl-4-phenyl-1,2,3,6-tetrahydropyridine (MPTP) can cause parkinsonism in humans. ${ }^{28-30}$ It has been suggested that other MPTP-like neurotoxins may be present in the environment. Case-control studies examining the influence of environmental factors have generally demonstrated a relationship with rural living and the onset of PD. ${ }^{31-37}$ This is controversial, however, and recent research has found either a weak or no association with rural living. ${ }^{6.38 .39}$

Geographic variation studies in Canada generally support the environmental model of PD; showing an uneven geographic distribution. ${ }^{14-16.36 .40}$ The highest prevalence rates, in Canada, are found among the western-most provinces (British Columbia, Alberta, Saskatchewan, Manitoba). ${ }^{14-16}$ Additional support for the environmental factor theory comes from geographic variation studies conducted in the United States. Kurtzke and Goldberg ${ }^{10}$ examined mortality rates between 1959 and 1961 and noted that rates followed a somewhat north-south distribution with the northern tier of states being the highest. As a follow up to the Kurtzke and Goldberg study, Lilienfeld et al. ${ }^{12}$ examined mortality rates between 1980 and 1988 and found that, although the distribution of rates remained uneven, the pattern had shifted away from a north-south gradient to a less defined distribution. Lilienfeld et al. ${ }^{12}$ concluded that this implied an environmental influence in the etiology of PD which may be shifting over time.

The present study examines the geographic distribution of PD within the Province of Alberta with the purpose of better defining geographic variations.

\section{METHOD}

Using the claims administrative data from the Alberta Health Care Insurance Plan (AHCIP), a cohort of all individuals registered with the AHCIP (2.4 million) was extracted and followed for the five-year period, April 1, 1984 to March 31, 1989. No new members were admitted to the cohort and an attrition rate (including migration and mortality) of $6 \%$ per year was observed, leaving 1.8 million people. The AHCIP contains the physician billing information for all registered residents of the Province of Alberta. Registration with the AHCIP is required of all residents of the province and is virtually complete.

All individuals among the cohort who had at least one physician encounter over the study period in which a diagnostic code for PD was provided were extracted and subdivided by five year age groups, sex and census division (CD) of residence. Codes from the International Classification of Diseases, 9th revision ${ }^{41}$ were used to identify cases (ICD-9 no. 332).
The Province of Alberta is divided into 19 census divisions (Figure 1). The data presented include an additional census division (CD 98) comprised of individuals for whom a resident address could not be confirmed. Individuals who could not be assigned to a $\mathrm{CD}$ accounted for $1.03 \%$ of the cohort and were excluded from the assessment of geographic variations.

Prevalence rates were calculated based on the number of individuals registered with the AHCIP as of January I, 1985. Using the direct method, prevalence rates were age standardized for each census division to the 1986 Alberta census population. ${ }^{42.43}$ Age standardization was designed to minimize the effects of age when comparing different populations. Standardized morbidity

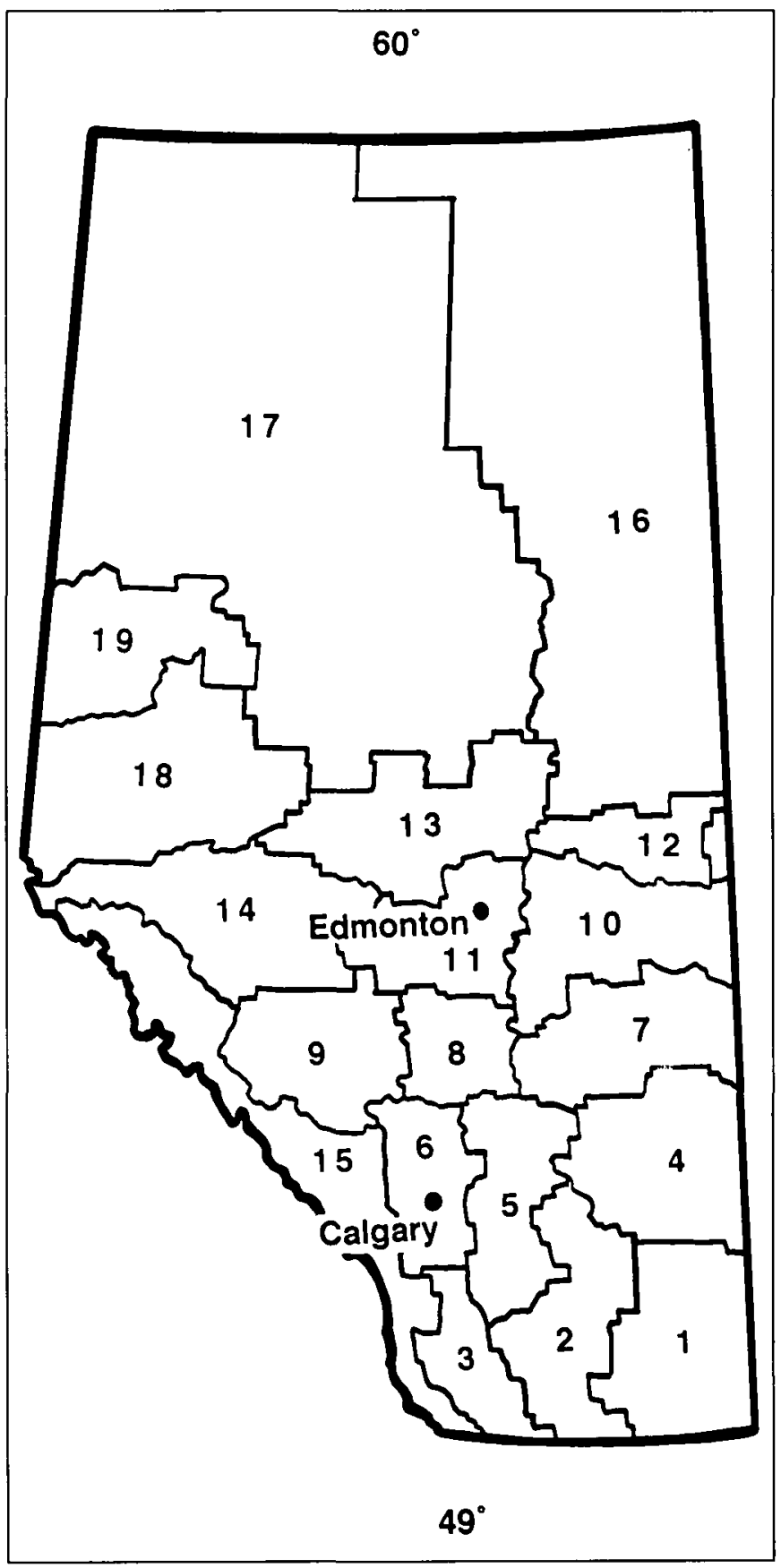

Figure I-Census divisions within the Province of Alberta. 
ratios (SMRs) were calculated, by sex, for each census division, with statistical significance assessed using a Poisson Ratio Test. ${ }^{44}$ A SMR is the ratio of the number of observed events to the number expected. To assess differences in the prevalence rates across census divisions for both sexes, a $\chi^{2}$ test for proportions was performed. ${ }^{45}$ Sex differences within each census division and for the province as a whole were evaluated using a $\chi^{2}$ test. ${ }^{45}$

\section{RESULTS}

Between April 1, 1984 and March 31, 1989, 5,903 (3,021 males; 2,882 females) cases of PD were identified, among the cohort, giving an overall crude prevalence rate of 244.4 per 100,000 population ( 239.8 for females; 248.9 for males). The mean age of the cases was 68.4 years $(69.1$ for females; 67.7 for males) and $81 \%$ of the cases ( $80 \%$ of males; $83 \%$ of females) were 60 years of age or older. The distribution of prevalence rates by age and sex can be found in Figure 2 .

For the province as a whole, prevalence rates did not differ significantly between the sexes. Analysis within each census division found only two census divisions had a statistically significant sex difference (CD 3 and 10) with males having the higher prevalence in both (Table 1). Table 2 displays the SMRs for each census division by sex. For males, nine census divisions had statistically significant SMRs, with four displaying a significant excess morbidity risk (CD 5,7,10,13) and five displaying a low morbidity risk (CD $6,11,14,16,17$ ). For females, seven census divisions had significant SMRs with six showing an excess morbidity risk (CD 1,2,5,7,10,13) and only one displaying a low risk (CD 16) of PD.

Comparisons across census divisions found a statistically significant difference for both males $\left(\chi^{2}=890.99\right.$, d.f. $=18, p<$ $0.001)$ and females $\left(\chi^{2}=424.51\right.$, d.f. $\left.=18, p<0.001\right)$. For further analysis, census divisions were grouped into three geographic regions: North (CD 12,13,16-19), Central (CD 7-11,14), and South $(C D 1-6,15)$. Both males $\left(\chi^{2}=19.94\right.$, d.f. $\left.=2, p<0.01\right)$ and females $\left(\chi^{2}=32.78\right.$, d.f. $\left.=2, p<0.01\right)$ were found to vary across these three regions with both having their highest rates in the Central region of the province. The lowest rate for males was found in the North area, while the South area was the lowest for females.

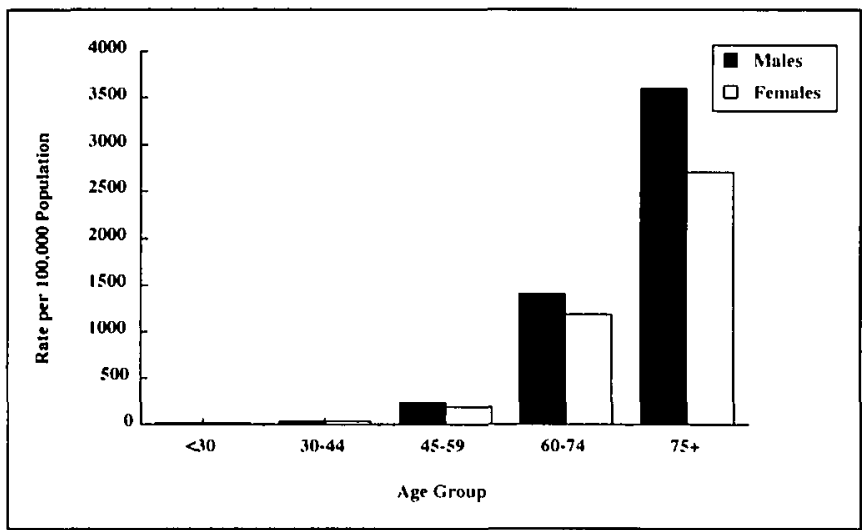

Figure 2 - Distribution of crude prevalence rates of Parkinson's disease per 100,000 population by age group and sex.

\section{Discussion}

A number of limitations with this study are acknowledged. The prevalence rates reported are based on an individual with PD utilizing a medical service and receiving a diagnostic code for PD. It is possible for an individual with PD to not visit a physician and therefore not be included in the calculation of

Table 1. Age-standardized prevalence rates by census division and by sex.

\begin{tabular}{crrrr}
\hline \multirow{2}{*}{$\begin{array}{c}\text { Census } \\
\text { Division }\end{array}$} & \multicolumn{2}{c}{ Males } & \multicolumn{2}{c}{ Females } \\
\cline { 2 - 4 } & Rate & \multicolumn{1}{c}{$\mathbf{n}^{\mathbf{a}}$} & Rate & \multicolumn{1}{c}{$\mathbf{n}$} \\
\hline 1 & 318.8 & 106 & 220.1 & 87 \\
2 & 276.9 & 185 & 212.9 & 167 \\
3 & 336.2 & 72 & $177.6^{*}$ & 44 \\
4 & 239.6 & 20 & 223.6 & 19 \\
5 & 236.5 & 67 & 237.6 & 64 \\
6 & 251.2 & 676 & 205.2 & 729 \\
7 & 336.8 & 95 & 314.7 & 96 \\
8 & 259.0 & 149 & 247.2 & 162 \\
9 & 250.8 & 19 & 350.3 & 24 \\
10 & 329.7 & 201 & $213.6^{*}$ & 137 \\
11 & 300.5 & 998 & 239.0 & 994 \\
12 & 274.4 & 64 & 275.0 & 63 \\
13 & 281.8 & 105 & 224.7 & 82 \\
14 & 317.5 & 30 & 167.6 & 17 \\
15 & 243.0 & 24 & 137.4 & 18 \\
16 & 154.4 & 16 & 189.3 & 17 \\
17 & 314.1 & 54 & 241.9 & 36 \\
18 & 63.6 & 3 & 99.3 & 3 \\
19 & 370.8 & 122 & 339.2 & 112 \\
$98^{\mathrm{b}}$ & 229.6 & 15 & 180.1 & 11 \\
Total & 269.3 & 3,021 & 224.8 & 2,882 \\
\hline
\end{tabular}

" $\mathrm{p}<0.01$

aTotal number of diagnoses given for Parkinson's Disease among the cohort.

${ }^{b} \mathrm{CD} 98$ consists of all individuals who could not be assigned to any other $\mathrm{CD}$.

Table 2. Standardized morbidity ratios by census division and sex.

\begin{tabular}{ccc}
$\begin{array}{c}\text { Census } \\
\text { Division }\end{array}$ & \multicolumn{2}{c}{ Standardized Morbidity Ratio } \\
\cline { 2 - 3 } 1 & Males & Females \\
2 & 1.18 & $1.38^{* *}$ \\
3 & 1.14 & $1.34^{*}$ \\
4 & 1.12 & 1.29 \\
5 & 1.28 & 1.38 \\
6 & $1.41^{* *}$ & $1.36^{*}$ \\
7 & $0.75^{* *}$ & 0.99 \\
8 & $1.35^{* *}$ & $1.48^{* *}$ \\
9 & 1.02 & 1.15 \\
10 & 0.95 & 0.91 \\
11 & $1.50^{* *}$ & $1.63^{* *}$ \\
12 & $0.81^{* *}$ & 1.02 \\
13 & 1.02 & 1.01 \\
14 & $1.29^{*}$ & $1.35^{*}$ \\
15 & $0.70^{*}$ & 0.80 \\
16 & 0.80 & 1.11 \\
17 & $0.41^{* *}$ & $0.38^{* *}$ \\
18 & $0.69^{*}$ & 0.65 \\
19 & 0.67 & 0.47 \\
Total & 0.85 & 0.88 \\
\hline * $<<0.05$ & 1.00 & 1.00 \\
$*$ p $<0.01$ & & \\
& & \\
\hline
\end{tabular}


rates. However, we assumed that a $P D$ patient would have at least one service over the five year period in which a diagnosis of PD would be given. Another potential concern is regarding the accuracy of diagnosis. We were not able to confirm the accuracy of the diagnoses of PD in this retrospective review. Reliability and validity of the use of claims administrative data in epidemiologic studies has been established by Roos et al. ${ }^{46}$ Given the strength of the variations noted, a substantial rate of misdiagnosis would be needed to negate the results. Also, the values reported in the present study are consistent with the prevalence rates for Canada estimated by Rajput. ${ }^{4}$

The data which we acquired did not include information on birthplace, place(s) and duration of residence throughout life, age of onset or severity of the disorder. Despite these limitations, the present study has the advantage of using the health care claims of the entire population of the province and should be relatively complete in case ascertainment. Patients with very early PD may not have been coded as such; the reported prevalence may therefore be a slight underestimate of the true prevalence. This study provides an overview of the prevalence and distribution PD in Alberta and supplies relevant information for the development of future studies. It provides information which can be used for planning a more directed approach in the development of future studies. For example, case-control studies could compare high and low prevalent areas and collect the data missing from the AHCIP database.

It is evident from the present study that cases of PD are unevenly distributed across census divisions within Alberta for both sexes. The highest rates of PD, for both sexes, were found in census divisions located in the central part of the province. CDs 7, 9 and 19 had the highest prevalence rates. CD 7 and CD 9 both have over $65 \%$ of the population residing in rural areas, while CD 19 had $40 \%$ residing in rural areas. ${ }^{47}$ Generally, these census divisions have sparsely populated areas with the majority of the population living in rural areas. These results support other research showing a relationship between PD and rural living. $14,15,33,36-40,48$ The uneven distribution of cases also offers support towards an environmental factor theory of etiology.

Further support for an environmental factor theory of etiology is evident upon examination of the SMRs for each census division. The census divisions containing Alberta's two largest cities had a statistically significantly reduced risk of PD for males, while the census divisions displaying a statistically significant excess morbidity risk were in primarily rural census divisions. Three of the four census divisions with low SMRs had less than $25 \%$ of the population residing in rural areas. Given that the data were derived from health care records of the entire provincial population, and that individuals were allocated to a census division based on their resident address, and not place of diagnosis, case ascertainment is believed to be relatively complete and the geographic differences would therefore appear valid.

The present study found no sex difference for the province as a whole. In fact, only two census divisions (CD 3 and 10) displayed a statistically significant difference, with males being higher in both. Lack of a sex difference supports the findings of Semchuk et al. ${ }^{6}$ and Rajput et al., ${ }^{3}$ but, opposes the findings of a number of other studies. ${ }^{10.12 .14,15,34,48}$ The similar geographic distribution between the sexes implies that similar factors may be associated with onset for both sexes.
Diamond et al. ${ }^{50}$ have found that males and females display similar patterns of disease progression. Differences may, however, be present in terms of severity. In Canada, males have been found to have higher hospitalization rates for PD. ${ }^{15}$ The higher rate among males in rural areas may be related to occupational exposures. For example, Semchuk et al. ${ }^{51}$ have reported an increased risk of PD associated with herbicide use. Further research is needed to better define occupational exposures particularly in rural areas which may lead to the onset of PD.

Although this study offers support for an environmental factor etiology of PD, the level and type of influence cannot be determined without further study. It may be useful to examine differences and similarities within and between high and low prevalent census divisions. Such a comparison may offer insight into possible environmental factors associated with the onset of PD. Further research is needed to determine if males and females differ in terms of disease severity and how this may relate to environmental factors.

\section{ACKNOWLEDGEMENTS}

The authors wish to acknowledge the helpful comments and advice received from Dr. W.R. Wayne Martin, Alec Campbell, Brian Alleyne, George Flynn, John Shaw, and Dr. Michel Joffres. Also, the authors wish to thank Hassanali Walji for data entry and the systems staff from the Information Technology Division of Alberta Health, for extracting the data.

\section{REFERENCES}

1. Gilroy J, Holliday PL. Basic Neurology. New York: Macmillan Publishing Co., Inc., 1982.

2. Koller WC. The diagnosis of Parkinson's disease. Arch Intern Med 1984; 144: 2146-2147.

3. Rajput AH, Uitti RJ, Rajput AH. Neurological disorders and services in Saskatchewan - a report based on provincial health care records. Neuroepidemiology 1988; 7: 145.151.

4. Rajput AH. Frequency and cause of Parkinson's disease. Can J Neurol Sci 1992; 19: 103-107.

5. Rajput AH, Offord KP, Beard CM, Kurland LT. Epidemiology of parkinsonism: incidence, classification, and mortality. Ann Neurol 1984; 16: 278-282.

6. Semchuk KM, Love EJ, Lee RG. Parkinson's disease and exposure to rural environmental factors: a population based case-control study. Can J Neurol Sci 1991; 18: 279-286.

7. Diamond SG, Markham CH, Hoehn MM, McDowell FH, Muenter MD. An examination of male-female differences in progression and mortality of Parkinson's disease. Neurology 1990; 40: 763-766.

8. Haerer AF, Anderson DW, Schoenberg BS. Survey of major neurologic disorders in a biracial United States population: the Copiah County study. South Med J 1987; 80: 339-343.

9. Schoenberg BS, Anderson DW, Haerer AF. Prevalence of Parkinson's disease in the biracial population of Copiah County, Mississippi. Neurology 1985; 35: 841-845.

10. Kurtzke JF, Goldberg ID. Parkisonism death rates by race, sex, and geography. Neurology 1988; 38: 1558-1561.

11. Lux WE, Kurtzke JF. Is Parkinson's disease acquired? Evidence from a geographic comparison with multiple sclerosis. Neurology 1987; 37: 467-471.

12. Lilienfeld DE, Sekkor D, Simpson S, et al. Parkinsonism death rates by race, sex and geography: a 1980s update. Neuroepidemiology 1990; 9: 243-247.

13. Lilienfeld DE, Chan E, Ehland J, et al. Two decades of increasing mortality from Parkinson's disease among the U.S. elderly. Arch Neurol 1990; 47: 731-734.

14. Svenson LW. Geographic distribution of deaths due to Parkinson's disease in Canada: 1979-1986. Mov Disord 1990; 5: 322-324. 
15. Svenson LW. Regional disparities in the annual prevalence rates of Parkinson's disease in Canada. Neuroepidemiology 1991; 10: 205-210.

16. Svenson LW, Campbell RL, Hawkswell P. The geographic distribution of Alzheimer's disease and Parkinson's disease in Canada: a comparison. Paper presented at the Second Canadian Epidemiology Research Conference, Edmonton, Canada, May 1991.

17. Calne DB. Current views on Parkinson's disease. Can J Neurol Sci 1983; 10: 11-15.

18. Calne DB. Current concepts on the etiology of Parkinson's disease. Mov Disord 1989; 4 (Suppl 1): S11-S14.

19. Bell J, Clark AJ. A pedigree of paralysis agitans. Ann Eugen 1926; l: $455-462$.

20. Golbe LI, Di Iorio G, Bonavita V, Miller DC, Duvoisin RC. A large kindred with autosomal dominant Parkinson's disease. Ann Neurol 1990; 27: 276-282.

21. Marsden CD. Parkinson's disease in twins. J Neurol Neurosurg Psychiatry 1987; 50: 105-106 [letter].

22. Alonso MA, Otero E, D'Regules R, Figueroa HH. Parkinson's disease: a genetic study. Can J Neurol Sci 1986; 13: 248-251.

23. Roy M, Boyer L, Barbeau A. A prospective study of 50 cases of familial Parkinson's disease. Can J Neurol Sci 1983; 10: 37-42.

24. Ward CD, Duvoisin RC, Ince SE, et al. Parkinson's disease in 65 pairs of twins and in a set of quadruplets. Neurology 1983; 33 : 815-824.

25. Calne S, Schoenberg B, Martin W, et al. Familial Parkinson's disease: possible role of environmental factors. Can J Neurol Sci 1987; 14: 303-305

26. Ebmeier KP, Mutch WJ, Calder SM. Does idiopathic parkinsonism in Aberdeen follow intra-uterine influenza? J Neurol Neurosurg Psychiatry 1989; 52: 911-913.

27. Mattock C, Marmot M, Stern G. Could Parkinson's disease follow intra-uterine influenza - a speculative hypothesis. J Neurol Neurosurg Psychiatry 1988; 51: 753-756.

28. Langston JW, Ballard P, Tetrud JW, Irwin I. Chronic parkinsonism in humans due to a product of meperidine-analog synthesis. Science 1983; 219 : 979-980.

29. Burns RS, LeWitt PA, Ebert MH, Pakkenberg H, Kopin IJ. The clinical syndrome of striatal dopamine deficiency: parkinsonism induced by 1 -methyl-4-phenyl-1,2,3,6-tetrahydropyridine (MPTP). N Engl J Med 1985; 312: 1418-1421.

30. Testa B, Naylor R, Costall B, Jenner P, Marsden CD. Does an endogenous methylpyridinium analogue cause Parkinson's disease? J Pharm Pharmacol 1985; 37: 679-680.

31. Bharucha NE, Bharucha EP, Bharucha AE, Bhise AV, Schoenberg BS. Prevalence of Parkinson's disease in the Parsi community of Bombay, India. Arch Neurol 1988; 45: 1321-1323.

32. Hertzman C, Wiens M, Bowering D, Snow B, Calne D. Parkinson's disease: a case control study of occupational and environmental risk factors. Am J Indust Med 1990; 17: 349-355.
33. Ho SC, Woo J, Lee CM. Epidemiologic study of Parkinson's disease in Hong Kong. Neurology 1989; 39: 1314-1318.

34. Kessler II. Epidemiologic studies of Parkinson's disease III. A community-based survey. Am J Epidemiol 1972; 96: 242-254.

35. Koller W, Vetere-Overfield B, Gray C. et al. Environmental risk factors in Parkinson's disease. Neurology 1990; 40: 1218-1221.

36. Rajput AH, Uitti RJ, Stern W, Laventy W. Early onset Parkinson's disease in Saskatchewan - environmental considerations for etiology. Can J Neurol Sci 1986; 13: 312-316.

37. Tanner CM, Chen B, Wang W, et al. Environmental factors and Parkinson's disease: a case-control study in China. Neurology 1989; 39: 660-664.

38. Stern M, Dulaney E, Gruber SB, et al. The epidemiology of Parkinson's disease: a case control study of young-onset and oldonset patients. Arch Neurol 1991; 48: 903-907.

39. Zayed J, Ducic G, Campanella G, et al. Facteurs environmenteaux dans l'etiologie de la maladie de Parkinson. Can J Neurol Sci 1990; 17: 286-291.

40. Rajput AH, Uitti RJ, Stern W, et al. Geography, drinking water chemistry, pesticides and herbicides and the etiology of Parkinson's disease. Can J Neurol Sci 1987; 14: 414-418.

41. Practice Management Corporation. International Classification of Diseases, 9th Revision - Clinical Modification, 3 ed., 1989.

42. Kramer MS. Clinical epidemiology and biostatistics: a primer for clinical investigators and decision-makers. New York: SpringerVerlag, 1988.

43. Lilienfeld AM, Lilienfeld DE. Foundations of epidemiology. New York: Oxford University Press, 1980.

44. Bailar JC, Ederer F. Significance factors for the ratio of a Poisson variable to its expectation. Biometrics 1964; 20:639-643.

45. Fleiss JL. Statistical methods for rates and proportions. New York: John Wiley \& Sons, 1981.

46. Roos LL, Nicol JP, Cagerge SM. Using administrative data for longitudinal research: comparisons with primary data collection. J Chron Dis 1987; 40: 41-49.

47. Statistics Canada. Urban areas - population and dwelling counts. Ottawa: Minister of Industry, Science and Technology, 1992.

48. Tanner CM, Chen B, Wang W-Z, et al. Environmental factors in the etiology of Parkinson's disease. Can J Neurol Sci 1987: 14: 419-423.

49. Kurtzke JF, Murphy FM. The changing patterns of death rates in parkinsonism. Neurology $1990 ; 40 ; 42-49$.

50. Diamond SG, Markham CH, Hoehn MM, McDowell FH, Muenter MD. An examination of male-female differences in progression and mortality of Parkinson's disease. Neurology 1990; 40: $763-766$.

51. Semchuk KM, Love EJ, Lee RG. Etiology of Parkinson's disease: a test of the multifactorial hypothesis. Can J Neurol Sci 1992; 19: 251 . 